so vereinigen, daß ein kleiner Herd dieses Gebietes eine Kompensation unmöglich macht. Die Bedeutung dieser Zone von diesem Standpunkt hat er schon vor einigen Jahren an Fällen mit ganz beschränkten Herden gezeigt.

8. Herr A. B oettiger-Hamburg:

\title{
Über Agraphie.
}

Vortr. berichtet über einen Fall reiner motorischer Agraphie. Ein 19 jähriger junger Mensch schießt sich am 25. IV. 1921 in suizidaler Absicht mit einem kleinen Revolver eine Kugel in die rechte Kopfseite und wird umgehend ins Krankenhaus gebracht. Hier verworren aufgenommen, bietet in den ersten Tagen das Bild eines SensorischAphasischen, gleichzeitig Verdacht auf rechtsseitige Hemianopsie; es besteht Seelenlähmung des linken Armes mit Analgesie desselben, ferner Oppenheim rechts, Bahinski rechts angedeutet. Allmähliche Aufhellung; bereits nach 2 Tagen läßt sich motorische und sensorische Aphasie ausschalten, ebenso Hemianopsie. Nach 14 Tagen vollkommen psychisch frei. Analgesie des linken Armes besteht noch, keine Aphasie, keine Alexie. Aber totale Agraphie, die motorische, cheiro-kinästhetische Form derselben. Kein Buchstabe, keine Figur, kaum eine Zahl. Schreibbewegungsvorstellungen fehlen. Keine sonstige Apraxie. Im Verlaufe von weiteren 3 Wochen stellte sich die Schrift großenteils wieder her, besonders noch Schwierigkeiten bei hastigem Schreiben. selbst 21/2 Monate nach dem Suizid kommen noch Fehler beim Schreiben und Versagen einzelner Buchstaben vor. Pat. ging wieder in seine Ingenieurschule. Hier bemerkt er als einzige sonstige Störung, daß ihm die Differential- und Integralrechnung, die ihm sonst keine Schwierigkeiten gemacht hatte, jetzt schwerer fällt. Die Analgesie des linken Armes hatte sich verloren bis auf einen geringen Rest an den zwei Endgliedern der Finger. Die Röntgenplatte, die ebenso wie Schriftproben demonstriert wurde, zeigt das Geschoß an der Innenwand des linken Os parietale, unterste Partie. Der Sitz entspricht dem hintersten Teil der I. Temporalwindung, dicht unterhalb des Gyrus supramarginalis. Boettiger folgert aus seiner Beobachtung, 1. daß die Schreibbewegungsvorstellungen ein eigenes Zentrum in der Hirnrinde der linken Hemisphäre haben, wie ja dem Lesen auch ein eigenes Zentrum zukommt, und 2. daß dieses Zentrum seinen Sitz hat in dem 
hintersten Teil der 1. Temporalwindung. Die Gründe zu diesen Schlußfo'gerungen, die auf physiologischem und patho-physiologischem, sowie klinischem Gebiete liegen, werden eingehend erörtert und die nur sehr spärliche einschlägige Literatur besprochen. Der Vortrag wird im Archiv für Psychiatrie erscheinen, wo weitere Einzelheiten nachzulesen sind.

\section{Aussprache:}

Herr K. Goldstein (Frankfurt a. M.): Soweit nach der kurzen Mitteilung ein Urteil möglich ist, scheint G. keine reine motorische Agraphie vorzuliegen, sondern der Rest einer ideatorischen Apraxie. G. warnt außerdem vor der Benutzung von Röntgenbildern von. Schußverletzungen für lokalisatorische Zwecke. Er hebt weiter hervor, daß eine umschriebene Lokalisation weder der reinen Alexie noch der Apraxie seiner Meinung anzunehmen ist; es handelt sich um Teilerscheinungen weitumfassenderer Funktionsstörungen und dementsprechend Schädigungen weit umfassenderer Gebiete, als deren schwerste Funktionsstörung die Alexie oder Agraphie zurückbleibt, die so als isolierte imponieren.

Herr Boettiger (Schlußwort): Am Tage der ersten Feststellung der Agraphie wurde auch auf sonstige Erscheinungen von Apraxie geachtet. Es bestand durchaus keine solche, auch keine ideatorische. B. hält die Annahme eines eigenen Zentrums für die Schreibbewegungsvorstellungen aufrecht und verweist auf die interessanten Mitteilungen $A$ s c haffenburgs über soziale Schädigungen von Hirnverletzten des Krieges.

\section{Herr G. Voß-Düsseldorf:}

\section{Die Salvarsanbehandlung der multiplen Sklerose.}

Vortr. hat im Laufe des Jahres 1920 an 7 gleichzeitig auf der Nervenabteilung des Reservelazaretts Düsseldorf liegenden Fällen von multipler Sklerose Behandlungsversuche mit Neo- und Silbersalvarsan angestellt. Die Kranken standen im Alter zwischen 23 und 45 Jahren, nur einer von ihnen hatte bereits vor dem Kriege Erscheinungen typischer Art geboten. Auffällige ätiologische Faktoren lagen nicht vor, Lues war klinisch nicht vorhanden, ebenso fehlten schwere Infektionskrankheiten und Traumen. Wie leicht verständlich, führten alle Kranken ihr Leiden auf Überanstrengung im Felde zurück. Frhebliche hereditäre Bèlastung bestand in keinem der Fälle, die sämtlich ein typisches Bild boten, bis auf einen, bei dem wegen isolierter Paraplegie zeitweilig an Tumor medullae gedacht wurde. 